\title{
GAIA Level 3 Ectopic Pregnancy
}

National Cancer Institute

\section{Source}

National Cancer Institute. GAIA Level 3 Ectopic Pregnancy. NCI Thesaurus. Code

C128712.

GAIA Level 3 Ectopic Pregnancy is defined by four criteria: first, it does not qualify as either a Level 1 or a Level 2 Ectopic Pregnancy; second, gestational age is within the predefined range for the selected ectopic pregnancy definition as assessed by maternal and/or fetal parameters (Level 2-3) (Brighton Preterm Birth Gestational Age algorithm); third, a positive urine pregnancy test; fourth, no products of conception are found on endometrial curettage after a dilation and curettage procedure. 